\title{
Uncertainty quantification in fatigue crack-growth predictions
}

\author{
V. Giannella
}

Received: 8 April 2021 / Accepted: 15 February 2022/Published online: 1 March 2022

(C) The Author(s) 2022, corrected publication 2022

\begin{abstract}
The reliability of the damage tolerance approach to engineering design is affected by numerous sources of uncertainty that can lead to unsafe predictions, in turn jeopardizing the safety of structures. This work presents a robust stochastic framework for fatigue crack-growth predictions applied to a round bar under tension-compression loading conditions. Multi-source uncertainties were taken into account to derive the lifespan distribution for the bar in such a way to cover the uncertainties typically appearing in a structural integrity assessment. The sensitivity of each input variable was obtained and the influences of variables on the life predictions were derived and ranked accordingly.
\end{abstract}

Keywords Fatigue crack-growth · Uncertainty quantification - Material scattering · Variability · Damage tolerance $\cdot$ Life prediction $\cdot$ Stochastic

\section{List of symbols}

a Crack depth

$a_{0} \quad$ El-Haddad's parameter

$a_{\mu} \quad$ Mean value for crack depth

$a_{\sigma} \quad$ Standard deviation for crack depth

C Coefficient of NASGRO formulation

V. Giannella $(\square)$

Department of Industrial Engineering, University of Salerno, via Giovanni Paolo II, 132, Fisciano, SA, Italy

e-mail:vgiannella@unisa.it
$\mathrm{C}_{\mathrm{th}} \quad$ Curvature parameter for the $R$-dependent

$\Delta K_{\text {th }}$ calculation

$D \quad$ Specimen diameter

$D_{\mu} \quad$ Mean value for diameter

$D_{\sigma} \quad$ Standard deviation for diameter

$d a / d N \quad$ Crack-growth rate

$F \quad$ Load amplitude

$F_{\mu} \quad$ Mean value for load amplitude

$F_{\sigma} \quad$ Standard deviation for load amplitude

$f \quad$ Newman's crack closure coefficient

$g \quad$ Coefficient in the $K$ analytical equation

$m$ Exponent of NASGRO formulation for

Paris-like regime

$N_{f} \quad$ Fatigue life prediction

$n \quad$ Prediction counter

$K \quad$ Stress intensity factor

$K_{c} \quad$ Critical stress intensity factor

$K_{I} \quad$ Mode-I stress intensity factor

$K_{\max } \quad$ Maximum value of stress intensity factor

$K_{\min } \quad$ Minimum value of stress intensity factor

$P_{f} \quad$ Probability of failure

$\mathrm{p} \quad$ Exponent of NASGRO formulation for nearthreshold regime

q Exponent of NASGRO formulation for subcritical regime

$R \quad$ Stress ratio $=K_{\min } / K_{\max }$

$s_{\max } \quad$ Max stress applied

$\alpha \quad$ Constraint factor

$\Delta K \quad$ Range of stress intensity factor 


$\begin{array}{ll}\Delta K_{t h} & \begin{array}{l}R \text {-dependent threshold stress intensity factor } \\ \text { range }\end{array} \\ \Delta K_{t h, 0} & \begin{array}{l}\text { Threshold stress intensity factor range for } \\ \mathrm{R}=0\end{array} \\ \mu & \text { Mean value } \\ \sigma & \text { Standard deviation } \\ \sigma_{\text {nom }} & \text { Nominal stress value } \\ \sigma_{U T S} & \text { Ultimate tensile strength } \\ \sigma_{y s} & \text { Yield stress } \\ \sigma_{0} & \text { Flow stress } \\ \text { CGR } & \text { Crack-growth rate } \\ \text { CV } & \text { Coefficient of variation } \\ \text { FCG } & \text { Fatigue crack-growth } \\ \text { FEM } & \text { Finite element method } \\ \text { LEFM } & \text { Linear elastic fracture mechanics } \\ \text { RMS } & \text { Root mean square }\end{array}$

\section{Introduction}

Experimental measurements for designing fatigue-safe mechanical components often appear to have an inherent random nature, due to the numerous sources of uncertainty and variability affecting the phenomena under observation. Since the 1950s, dealing with the spread or scatter in fatigue lives played a vital role in ensuring acceptably low probabilities of structural failures. The earliest approaches to tackle this "fatigue variability" phenomenon were usually characterized by the generation of large sets of test data, resulting in very time consuming and expensive testing campaigns. Subsequently, once comprehended that this variability was an inherent part of the fatigue phenomenon, enhanced mathematical models and numerical simulations were developed to analyse the fatigue behaviour through thorough probabilistic approaches (Zhu et al. 2017, 2018a; Armentani et al. 2020; Niu et al. 2021; Klawonn et al. 2020). Since structural integrity of engineering components is directly affected by several aspects, e.g. geometrical factors, material scattering, statistical uncertainty, modelling approximations, human and judgement errors (Beretta et al. 2016a; Citarella and Apicella 2006; Sandberg et al. 2017; Endeshaw et al. 2017), quantifying and controlling these characteristics is essential to enhance the competitiveness in designing fatigue-safe products, e.g. as turbine engines, railway axles, shafts, etc.
(Citarella et al. 2016; Citarella and Perrella 2015; Giannella 2021a).

Engineering components generally fail due to irreversible micro-plastic deformations from which cracks are nucleated, generally at notches or at critical locations (Sepe et al. 2019; Romano et al. 2020; Giannella et al. 2018a). This process is followed by fatigue crack-growth (FCG) through the cross-section and, eventually, by the final failure of the whole component. Due to the limitations of modern smelting and casting technologies, there are some unavoidably initial defects in materials, such as air bubbles, holes or impurities that have to be taken into account directly at the designing stage (Zhu et al. 2018b, c; He et al. 2015). Additionally, defects and imperfections can also be induced by the manufacturing processes, from the more traditional (e.g. welding (Giannella et al. 2017a; Fellinger et al. 2018)) to the latest cutting-edge processes recently entering the industry (e.g. advanced welding procedures (Carlone et al. 2016; Rubino et al. 2020, 2021) or additive manufacturing (Caggiano et al. 2019, 2021)). Considering the inhomogeneous microstructure and non-uniform mechanical properties of metal materials, including crystal defects, grains boundary, dislocations, etc., cracks may encounter diversiform microstructures, in turn demonstrating variable strength against FCG. There are also further external sources of uncertainties originating from the scattering of material properties, geometrical dimensions and working environments that need to be taken into account (Zhu et al. 2020). As a result, the FCG process shows considerable variability even in "identical" repeated tests, thus leading to the definition of the widely accepted conception that, at least from a macroscopic point of view, FCG has inevitably stochastic characteristics.

In the fatigue design of components of mechanical systems, the various sources of uncertainty and variability have to be taken into account in order to guarantee a safe design (Fig. 1). These input sources can be broadly divided into two categories: aleatory and epistemic (Chernatynskiy et al. 2013). The first category comes from the inherent variation resulting from the physical process under observation or from the environmental conditions (Roy and Oberkampf 2011), with an impact on life prediction that cannot be reduced in size but needs to be quantified. The second category takes place where knowledge or accurate information is lacking and/or cannot be acquired at all: 


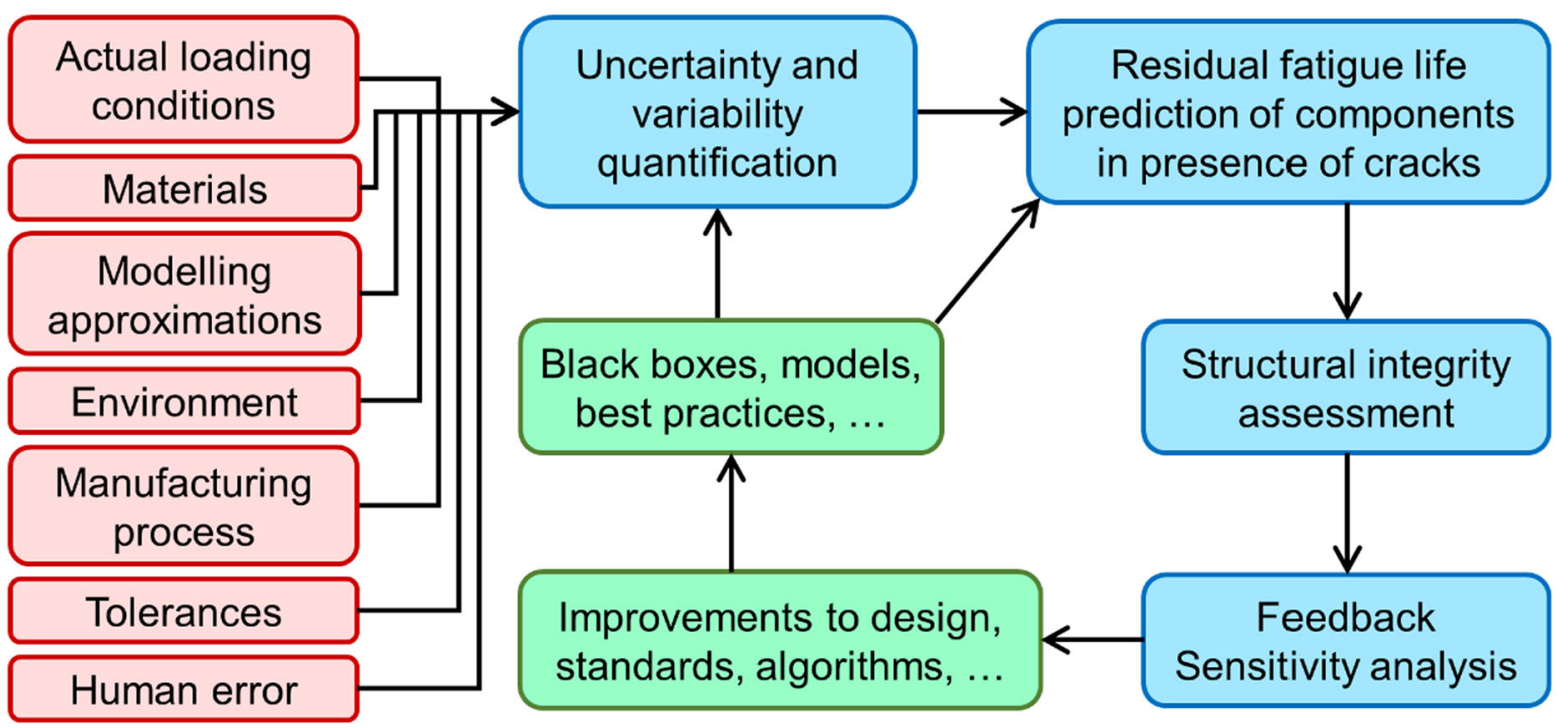

Fig. 1 Framework for fatigue crack-growth assessments under input data variability

these can be reduced after the acquirement of new information, through a better use of the available data and/or through more accurate modelling methods (Fig. 1).

Several studies have explored the possibility to choose safety factors from a probabilistic design perspective (Sepe et al. 2019; Grell and Laz 2010; Guida and Penta 2010; Beretta and Regazzi 2016). Most of the available research focused primarily on obtaining life predictions by considering slight perturbations on the loading conditions as well as small variations on the Crack-Growth Rates (CGRs) (Grell and Laz 2010; Guida and Penta 2010). The purpose of the current work was to quantify the effects of multiple sources of uncertainty and variability on the phenomenon of FCG for a simple case study, i.e. a cracked round bar under tension-compression loading (stress ratio $R=-1$ ). This investigation can be considered as an example case and the results can be used to better drive similar calculations performed on small components axially loaded. However, with the appropriate adjustments, this framework can be extended to larger and more complex industrial components in a straightforward manner.

A probabilistic framework is presented in this work for a fatigue reliability assessment considering multisource uncertainties. These primary sources of uncertainty were considered here as coming from: (i) the inherent scattering of material properties, (ii) the variability of the main geometrical dimensions of components, (iii) the statistical nature of the actual loading conditions. In this regard, although analytical methods exist in literature (Ciavarella and Papangelo 2018), a full computational approach was adopted to develop a probabilistic FCG assessment based on a vast set of experimental data available in literature. By using the NASGRO formulation, arranged in a stochastic way, residual fatigue life predictions were computed by taking account of the main input sources reported above, see also Fig. 2. Hence, the sensitivity of each basic random variable was derived and the influences of all variables on the residual life predictions were ranked accordingly.

The rest of this article is organised as follows.

Section 2 presents how variability sources were introduced in the NASGRO equations so as to account for of the scattering of material properties. Section 3 reports how the main geometrical dimensions and loading conditions were considered in a probabilistic perspective. Section 4 comprises an overall description of the procedure showing how all the previously described uncertainty sources were managed. Section 5 reports the results of the analyses providing some guidelines of general validity to advance the comprehension of the phenomenon. Finally, Sect. 6 concludes with the remarks of this article. 
Fig. 2 Case study schematic view, with highlight of the most relevant sources of uncertainty typically appearing in a residual life assessment

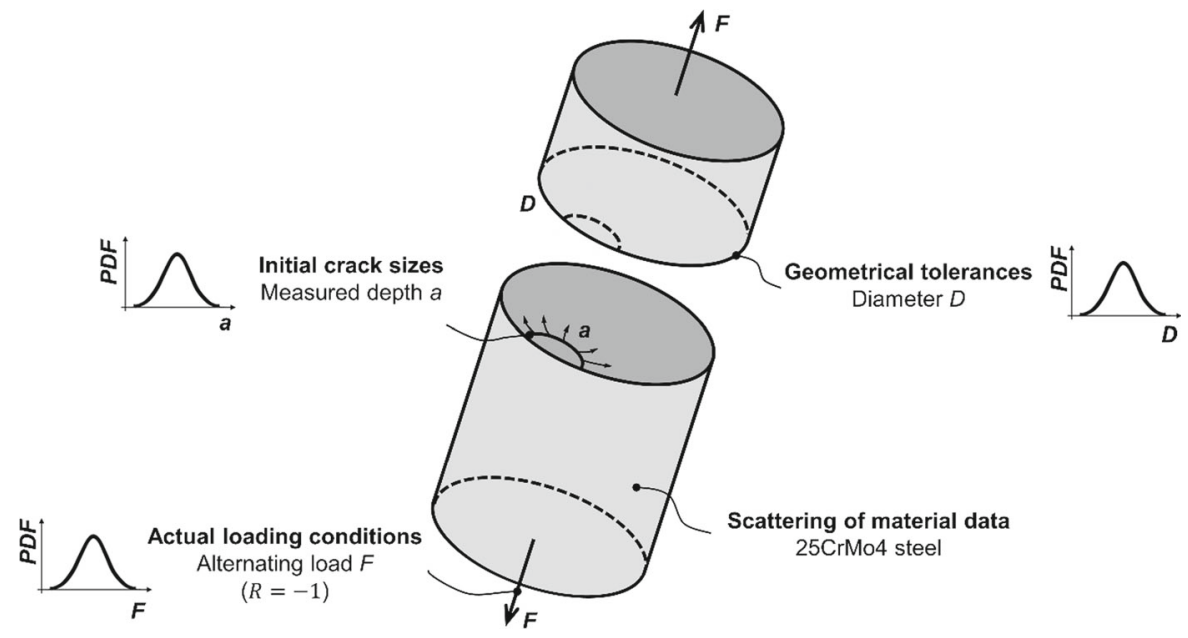

\section{Uncertainty in material properties}

FCG has an unavoidable stochastic nature that directly affects the accuracy of the life predictions for structures in presence of defects. Material properties variability, geometrical tolerances, pre-existing micro-structural defects and inaccurate loading conditions directly affect both crack nucleation and propagation phases (Zhu et al. 2017; Beretta and Regazzi 2016; Beretta and Carboni 2006; Beretta et al. 2010; Larsen et al. 2013), see Figs. 1 and 2. Through a better use of the available data and through more advanced modelling methods, improvements on the lifespan predictions can be obtained (Giannella et al. 2017b, 2018b, 2019a, b).

Even though advanced probabilistic approaches can provide the engineers with more robust information about the safety of structures (Zhu et al. 2017, 2018a; Armentani et al. 2020; Niu et al. 2021; Klawonn et al. 2020; Beretta et al. 2016a; Giannella 2021a; Sepe et al. 2019; Romano et al. 2020; Giannella et al. 2018a; Grell and Laz 2010; Guida and Penta 2010; Beretta and Regazzi 2016; Beretta and Carboni 2006), as a downside, these approaches often require vast sets of experimental data for their development to limit the statistical uncertainty. The material under analysis selected for this work was the $25 \mathrm{CrMo} 4$ steel (known also as EA4T grade in the railway industry), for which a vast set of FCG test data at $R=-1$ was available in literature (Luke et al. 2011; Náhlík et al. 2017; Pokorný et al. 2016a; Beretta et al. 2016b; Maierhofer et al. 2014; Wu et al. 2016; Varfolomeev et al. 2010; Project MARAXIL; Hu et al. 2021), see

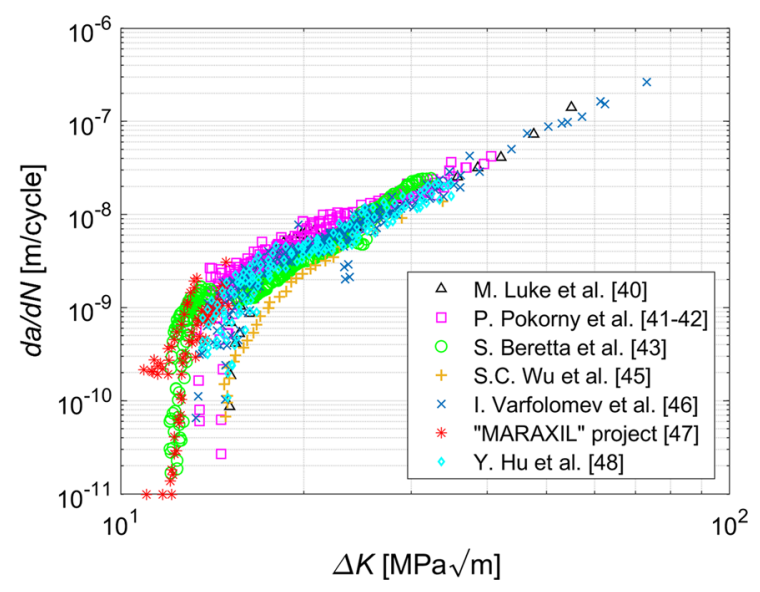

Fig. 3 25CrMo4 CGRs obtained by tests on full-scale axles and specimens $(R=-1)$

Fig. 3. Chemical composition of 25CrMo4 was reported in Table 1. According to Hu et al. (2021), the matrix is primarily comprised of bainite and martensite, with an average grain diameter of around $7.2 \mu \mathrm{m}$; this very fine microstructure and small grain size contribute to a low level of roughness-induced crack closure (Vojtek et al. 2019; Pokorný et al. 2017).

The adoption of a large set of FCG data allowed us to reduce the statistical uncertainty generally occurring when small sample sizes are used. Data in Fig. 3 exhibit a noteworthy scatter, in part attributable to the fact that different sizes and shapes of specimens were used for their derivation. This scatter in terms of CGRs can be considered as one of the primary causes of the ample variability of the residual life estimates. 
Table 1 Chemical composition of 25CrMo4 (values in \%)

\begin{tabular}{llllllll}
\hline $\mathrm{C}$ & $\mathrm{Si}$ & $\mathrm{Mn}$ & $\mathrm{P}$ & $\mathrm{S}$ & $\mathrm{Cr}$ & $\mathrm{Mo}$ & $\mathrm{Fe}$ \\
\hline $0.22-0.29$ & $0.40 \max$ & $0.6-0.9$ & $0.025 \max$ & $0.035 \max$ & $0.9-1.2$ & $0.15-0.3$ & Balance \\
\hline
\end{tabular}

Material data of Fig. 3 are generally aimed to calibrate a FCG law useful to perform life estimates for cracked components. A NASGRO FCG formulation was selected in this work and implemented in a stochastic way. The basic formulation enables the modelling of the three basic parts of a CGR diagram and is very popular in the scientific community at the present time to model "long cracks". Namely, the standard "damage tolerance" approach considered crack sizes of sufficiently large size to be present at the beginning of calculations, also to remove difficulties in the treatment of "short cracks". When this assumption is not applicable, the "short crack" regime has to be modelled, e.g. through a generalised Paris' law, see (Pugno et al. 2006).

The reader is referred to Newman (1984), Forman and Mettu (1990), NASGRO® (2019), Elber (1970), Elber and Rosenfeld (1971) and El-Haddad et al. (1979) for dedicated information about the derivation of the various elements of NASGRO along the years. As a downside of its generalizability, the calibration of a NASGRO requires up to 11 material parameters $\left(C, m, p, q, C_{t h}, \Delta K_{t h, 0}, K_{c}, \alpha, \sigma_{Y S}, \sigma_{U T S}, a_{0}\right)$ with consequent large efforts from the experimental standpoint for their derivation (Beretta and Carboni 2004; Giannella 2021b; Giannella et al. 2021). These parameters are required by the main NASGRO formula (Eq. 1) and by the formulae for the calculation of the $R$-dependant $\Delta K_{\text {th }}$ (Forman and Mettu 1990; NASGRO ${ }^{\circledR}$ 2019) (Eq. 2) and the plasticityinduced crack closure function $f$ (Forman and Mettu 1990; NASGRO® 2019) (Eqs. 3, 4).

$$
\begin{aligned}
& \frac{d a}{d N}=C\left[\left(\frac{1-f}{1-R}\right) \Delta K\right]^{m} \frac{\left(1-\Delta K_{t h} / \Delta K\right)^{p}}{\left(1-K_{\max } / K_{c}\right)^{q}}, \\
& \Delta K_{t h}=\Delta K_{t h, 0} \frac{\sqrt{a /\left(a+a_{0}\right)}}{\left[\frac{1-f}{\left(1-A_{0}\right)(1-R)}\right]^{1+C_{t h} R}},
\end{aligned}
$$

$$
\begin{aligned}
f & =\frac{K_{o p}}{K_{\max }} \\
& =\left\{\begin{array}{c}
\max \left(R, A_{0}+A_{1} R+A_{2} R^{2}+A_{3} R^{3}\right), R \geq 0 \\
A_{0}+A_{1} R,-2 \leq R<0
\end{array},\right.
\end{aligned}
$$

$\left.\begin{array}{l}A_{0}=\left(0.825-0.34 \alpha+0.05 \alpha^{2}\right)\left[\cos \left(\frac{\pi}{2} S_{\max } / \sigma_{0}\right)\right]^{1 / \alpha} \\ A_{1}=(0.415-0.071 \alpha) S_{\max } / \sigma_{0} \\ A_{2}=1-A_{0}-A_{1}-A_{3} \\ A_{3}=2 A_{0}+A_{1}-1\end{array}\right\}$.

Thanks to the stochastic implementation of NASGRO adopted here, fewer parameters need to be directly calibrated through test data. As a matter of fact, the calibration of a NASGRO generally implies the calibrations of its distinct parameters separately, representing a rather time consuming task. Moreover, this calibration procedure can be a further source of error since parameters are generally calibrated one at a time, often neglecting their mutual interactions.

The stochastic NASGRO formulation presented here reduces the human effort required by a manual calibration, increases the calibration accuracy by considering all the mutual interactions between parameters, guarantees the highest correlation with experimental test data.

This was achieved by directly inserting the NASGRO equations (Eqs. 1-4) in the MATLAB programming platform (MATLAB 2019). Only the most relevant parameters were considered as variable within the MATLAB routine, whereas those parameters which did not influence the life predictions in a significant way were kept as constants (Table 2 for their constant values). This classification in either constant or variable parameters was already discussed in previous research (Giannella 2021a, b, 2022). The remaining most relevant parameters of NASGRO, i.e. $C, m, p, \Delta K_{t h, o}$, were considered as uncorrelated random variables ranging within given ranges of variability, these latter defined with a trial-and-error 
Table 2 AA25CrMo4 material data

\begin{tabular}{llllllll}
\hline$\sigma_{U T S}[\mathrm{MPa}]$ & $\sigma_{y s}[\mathrm{MPa}]$ & $K_{c}[\mathrm{MPa} \sqrt{\mathrm{m}}]$ & $\alpha[-]$ & $q[-]$ & $a_{0}[\mathrm{~m}]$ & $v[-]$ & $C_{t h}[-]$ \\
\hline 708 & 554 & 131.56 & 3 & 5 & $3.81 \mathrm{e}-5$ & 0.32 & 0.115 \\
\hline
\end{tabular}

Table 3 Ranges of variability of the following $25 \mathrm{CrMo} 4$ NASGRO parameters

\begin{tabular}{lll}
\hline & Min value & Max value \\
\hline $\log _{10}(C)\left(C\right.$ in $\left.\mathrm{MPa}^{-m} \mathrm{~m}^{1-m / 2}\right)$ & -12 & -6.9 \\
$m[-]$ & 0 & 4 \\
$p[-]$ & 0 & 4.4 \\
$\Delta K_{t h, o}[\mathrm{MPa} \sqrt{\mathrm{m}}]$ & 5.8 & 8 \\
\hline
\end{tabular}

procedure in such a way to include all their potentially acceptable values. These ranges were listed in Table 3 .

Consequently, Monte Carlo simulations were performed. With reference to uncertainty of material parameters only, each simulation consisted in picking four material parameters randomly within their ranges so as to draw a CGR curve (through Eqs. 1-4). Then, the quality of fitting of this CGR curve was assessed through two Root Mean Square (RMS) errors that were used to define the quality of fitting of each curve for the near-threshold range and for the Paris' regime separately (see also (Giannella 2021a)). If both RMS errors resulted to be lower than cut-off threshold values (set to $3 \%$ ), the curve was used to compute a fatigue life prediction. Instead, when RMS errors resulted to be higher than thresholds, the CGR curve was judged as not acceptable, the corresponding set of parameters was immediately discarded and a new Monte Carlo simulation started.

Similar Monte Carlo simulation strategies were already proposed in literature (Annis 2004), where the need to take into account the mutual interactions between parameters was highlighted. Here, the validation of each CGR curve with the experimental data allowed them to be considered interconnected, therefore avoiding the issues highlighted in Annis (2004). The current Monte Carlo strategy was already validated in Giannella (2022) against the experimental test data available in Virkler et al. (1979), showing that it was able to predict both mean value and standard deviation of experimental life predictions. The reader is referred to Giannella (2021a, b, 2022) for further information about this procedure. Further details can also be found in Sect. 4 .

\section{Uncertainty in geometrical dimensions and loading conditions}

Geometrical tolerances between actual and design dimensions are inevitable due to the manufacturing processes or design margins (Zhan et al. 2000; Caiazzo et al. 2017). Their proper definition is essential in the engineering sphere to ensure the interchangeability and assemblability of components, to allow for power transmission through interference coupling mechanisms, to reduce costs of manufacturing, etc. Minor changes of geometrical dimensions of components may show critical influence on the stress-strain responses of actual components, thus yielding to much different fatigue performances (Hu et al. 2020). These aspects are even more important when dealing with FCG problems since very slight discrepancies on measurements of component dimensions and crack sizes can lead to orders of magnitude of discrepancies in terms of residual fatigue life predictions (Giannella 2021a; Giannella et al. 2021).

Regarding these aspects, geometrical uncertainty was considered here for the most relevant dimensions of the round bar with the aim of quantifying their influence on the residual life estimates. Namely, since the considered loading condition was a tensioncompression load cycle with $R=-1$, the bar diameter and the initial crack depth were the only dimensions considered as having relevant influence, see Fig. 2. These parameters were inputted in the MATLAB routine as following a normal distribution with user defined mean values and standard deviations, see Table 4 . The adoption of normal distributions for geometrical and loading variabilities can be considered as a common engineering practice (Zhu et al. 2017; Beretta et al. 2016a; Citarella and Apicella 2006; Guida and Penta 2010; Beretta and Regazzi 
Table 4 Parameters of normal distributions for geometrical dimensions and loading conditions; distributions shown in Fig. 4

\begin{tabular}{llll}
\hline & Distribution & Mean value $\mu$ & Standard deviation $\sigma$ \\
\hline Initial crack depth $a[\mathrm{~mm}]$ & Normal & 1 & 0.15 \\
Diameter $D[\mathrm{~mm}]$ & Normal & 18 & 0.27 \\
Load $F[\mathrm{kN}]$ & Normal & 63.6 & 0.95 \\
\hline
\end{tabular}

2016; Beretta and Carboni 2006). The primary contribution coming from the variability of bar diameter was expected to be the variation of the nominal stress $\sigma_{\text {nom }}=4 F_{\mu} / \pi D_{\mu}^{2}$, whereas the primary contribution given by the initial crack depth variation was expected to be the impact on the $K_{I}$ calculation (James and Mills 1988) as:

$$
\left\{\begin{array}{c}
K_{I}=\sigma_{\text {nom }} \sqrt{\pi a} \times g \times\left\{0.752+2.02\left(\frac{a}{D}\right)+0.37\left[1-\sin \left(\frac{\pi a}{2 D}\right)\right]^{3}\right\} \\
g=\frac{1.84}{\pi} \sqrt{\left[\tan \left(\frac{\pi a}{2 D}\right) /\left(\frac{\pi a}{2 D}\right)\right]} / \cos \left(\frac{\pi a}{2 D}\right)
\end{array} .\right.
$$

Contrary to numerous applications (Zhu et al. 2018b, c; Guida and Penta 2010; Beretta and Regazzi 2016; Giannella et al. 2017b, 2018b, 2019a, b; Luke et al. 2011; Náhlík et al. 2017; Pokorný et al. 2016a; Beretta et al. 2016b; Giannella and Perrella 2019; Shlyannikov et al. 2021; Ayhan and Demir 2021), no numerical simulations were needed to obtain the $K$ values along the crack-growth thanks to the simplicity of the case study considered here. Note from the Linear Elastic Fracture Mechanics (LEFM) assumption that slight discrepancies in terms of $K$ values can return much higher deviations in terms of CGRs due to (i) the amplification through the exponent $m$, (ii) the scattering of material data (Zhu et al. 2018b; Giannella et al. 2018b, 2019a; Ayhan and Demir 2021; Citarella et al. 2018), see Fig. 3. A nominal initial crack $a_{\mu}$ was arbitrarily defined as having a depth of $1 \mathrm{~mm}$, whereas a variation of $\pm 0.3 \mathrm{~mm}$ was envisaged through a standard deviation $a_{\sigma}$ of 0.15 (assuming a $\mu \pm 2 \sigma$ range). The geometrical tolerance for the diameter was approximately taken as $D_{\sigma}=0.015 D_{\mu}$ of variation from the designed nominal size $D_{\mu}$ equal to $18 \mathrm{~mm}$. The corresponding variation was therefore set up to $18 \pm 0.5 \mathrm{~mm}$ if considering that a range of $\mu \pm 2 \sigma$ covers nearly $95.5 \%$ of a normal distribution.

According to Eq. 5, the accuracy used to define the nominal stress $\sigma_{\text {nom }}$ can play a significant role in the accuracy of the $K$ calculation, in turn affecting the output life predictions. This means that not only the nominal loading conditions, but also their potential variations need to be quantified to allow for a safe life prediction. With reference to the current investigation, a nominal force $F_{\mu}$ of $63.6 \mathrm{kN}$ was considered, corresponding to a nominal stress $\sigma_{\text {nom }}$ of $250 \mathrm{MPa}$. The related coefficient of variation $C V$ was defined as $F_{\sigma} / F_{\mu}=0.015$, thus returning a $\pm 3 \%$ of variability in a $\pm 2 \sigma$ range. The final distributions defined for geometrical dimensions and loading conditions are shown in Fig. 4 whilst the related parameters are listed in Table 4.

\section{Stochastic procedure description}

Crack propagation phenomena are inherently stochastic and the solutions obtained deterministically are only limiting outcomes that do not allow for their comprehensive description. The stochastic procedure for the fatigue life assessment of the round bar was performed within a user-made MATLAB (MATLAB 2019) routine implementing the logic illustrated in Figs. 5 and 6. The routine considered as input data the variables presented in the previous Sects. 2 and 3 and provided as output the predictions of the residual fatigue lives estimated for the cracked round bar.

The procedure starts by reading the required input data, i.e. material parameters and their ranges of variability (Table 3), experimental data (in Fig. 1), the parameters defining variations for geometry and load (Table 4), the requested amount of predictions to perform (i.e. 1e5 Monte Carlo simulations). For each $n$-th simulation, the four material parameters $\left(C_{n}, m_{n}, p_{n}, \Delta K_{t h, 0, n}\right)$ are randomly sampled within their ranges so as to generate a $n$-th CGR curve. This latter is compared with the test data and, if judged as providing an acceptable fitting (see Sect. 2), an $n$-th fatigue life prediction is then computed. If not, a new 

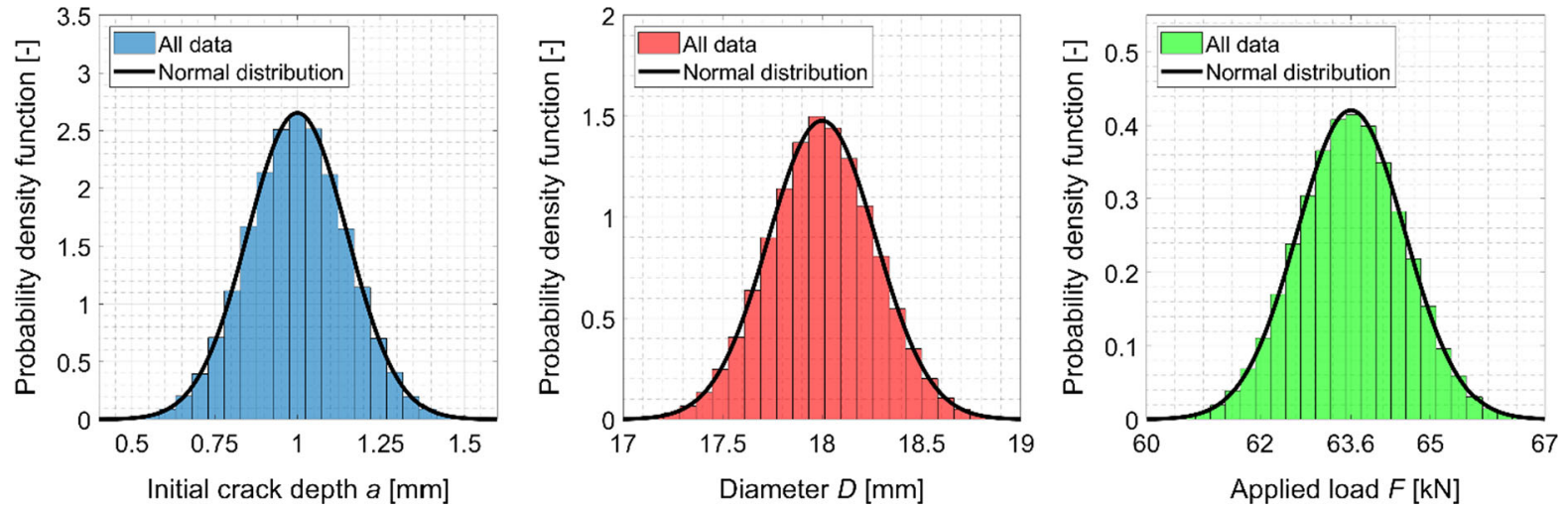

Fig. 4 Probability density functions for crack size uncertainty, geometrical tolerances and loading conditions

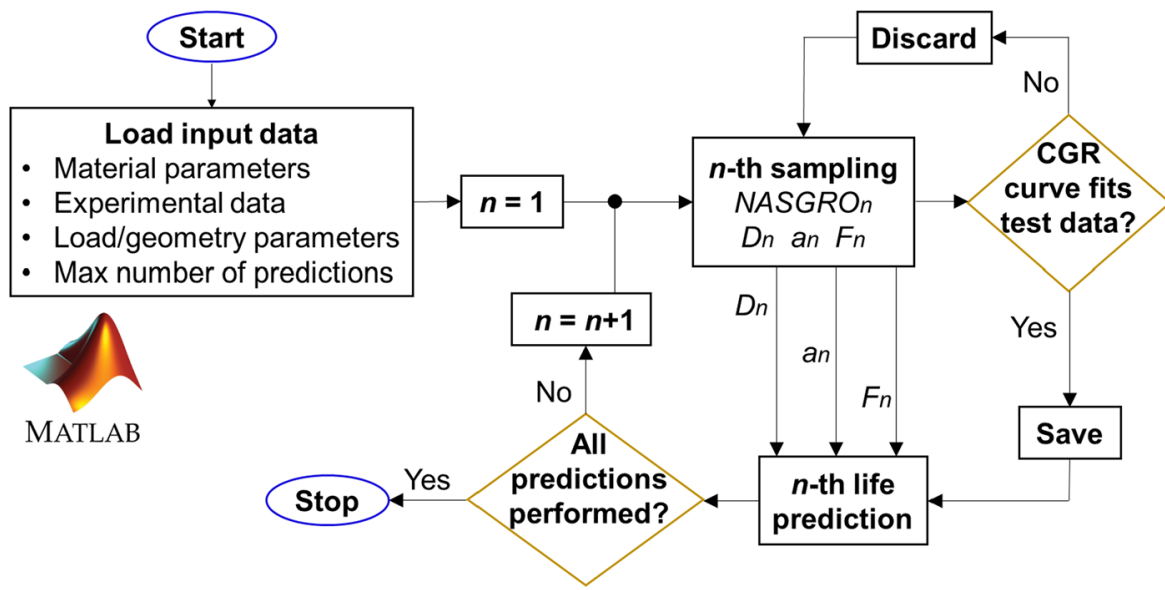

Fig. 5 Flowchart illustrating the stochastic approach implemented for the residual life predictions; $N A S G R O_{n}$ represents a $n$-th set of NASGRO material parameters; $D_{n}, a_{n}, F_{n}$ are

sampling starts until an $n$-th curve with an acceptable fitting is obtained. The procedure is then reiterated until the requested number of predictions is reached.

As shown in Figs. 5 and 6, the random nature of FCG phenomenon was quantified in order to achieve a probabilistic description that would account for the variabilities given by material parameters, actual loads and the main geometrical dimensions. With such an approach, the distribution of the fatigue life predictions with allowance for these main sources of uncertainty was obtained, thus leading to an improved and more thorough control over the safety of structures. Calculations were then performed at various levels of uncertainty for all input parameters so as to respectively three values for diameter, initial crack depth and force amplitude for a $n$-th prediction

provide a sensitivity analysis and to derive the influence of each basic variable on the life predictions.

\section{Results}

The residual life prediction of mechanical components subjected to cyclic loading is of paramount importance for industry. In this prospect, the presented procedure aimed to provide a robust tool capable to perform probabilistic fatigue life predictions by taking into account of the most typical sources of uncertainty appearing during a structural integrity assessment (Fig. 2). Through the input variables developed in Sects. 2 and 3 and the framework detailed in Sect. 4, it 


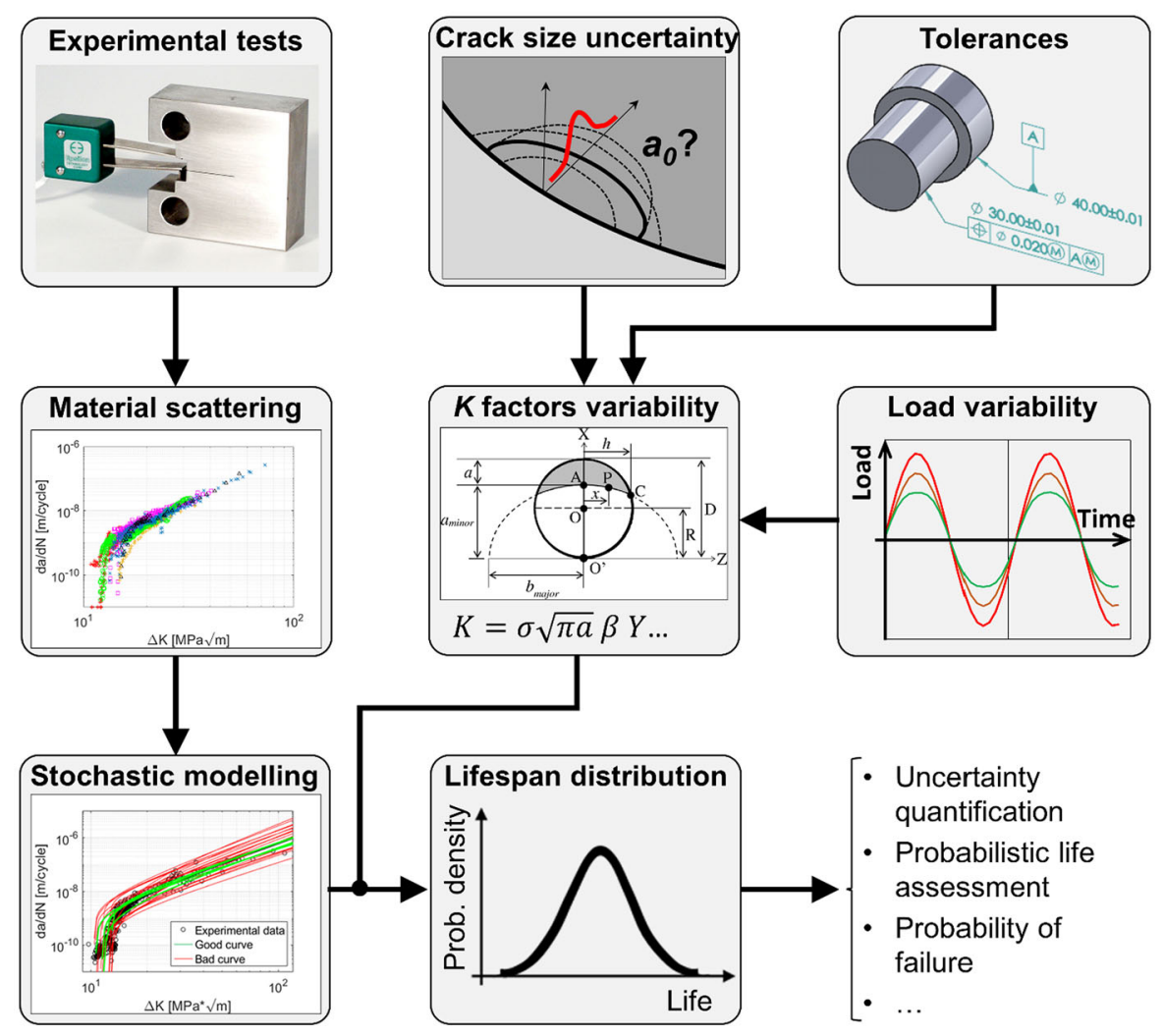

Fig. 6 Block diagram illustrating the stochastic procedure for residual life assessments

was possible to quantitatively evaluate the distribution of residual fatigue lives predicted for the bar.

Even though calculations were performed with all the data sets, some figures reported below comprised a reduced set of data to improve their readability.

Simulated CGR curves are shown in Fig. 7, as superimposed to the experimental data and to the bestfit CGR curve, i.e. the simulated CGR curve that provided the best fitting of material data (i.e. the lowest RMS errors). It can be noticed that a very good fitting of data was provided by simulations for both near-threshold and Paris-like range, where a vast set of experimental data was available. A worse correlation was instead noticed at very high $\Delta K$ values: this was expected because of the very few experimental data available in that region. Nevertheless, negligible impact on the predictions are expected from this poor correlation since most of the life of a component is generally predicted when $d a / d N$ is very low, i.e. when $\Delta K<15 \mathrm{MPa} \sqrt{ } \mathrm{m}$ (e.g. when cracks are still rather small). Instead, this issue is more relevant only when high $\Delta K$ are obtained at small crack sizes, e.g. at high applied load levels or when cracks nucleate in highly stressed locations.

A correlation matrix for NASGRO parameters $C$, $m, p, \Delta K_{t h, O}$ is reported in Fig. 8. Best-fit parameters are also reported in red. Best-fit parameters are those that returned the lowest RMS errors, i.e. they produced the CGR curve with the best correlation with experimental data. Generally, this is the only curve that is considered when using a deterministic approach to fracture and was highlighted here for a comparison.

The main diagonal shows the occurrences of the four material parameters that clearly do not follow a normal/lognormal distribution, as arbitrarily imposed a priori in several works (Caggiano et al. 2021; Chernatynskiy et al. 2013; Grell and Laz 2010; Guida and Penta 2010; Wu et al. 2016; Elber and Rosenfeld 1971). Out of the main diagonal, it can be observed that the material parameters are mostly uncorrelated, 


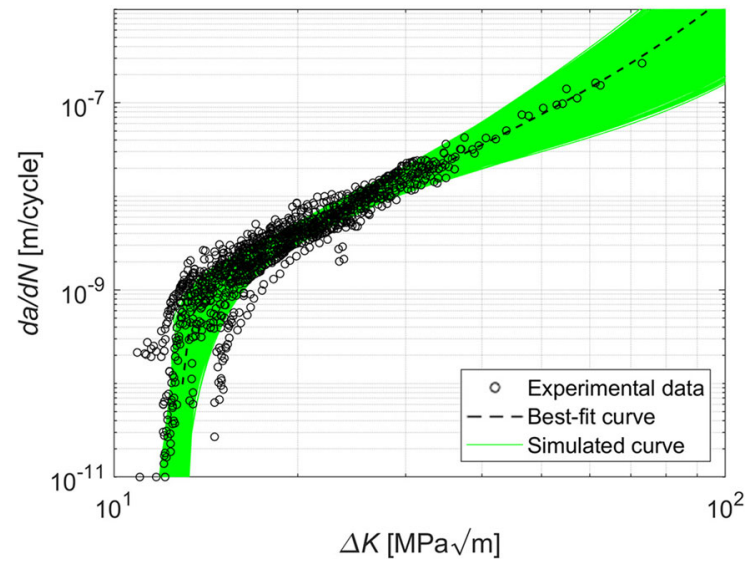

Fig. 7 Simulated CGR curves with highlight of the best-fit curve

with the exception of $\log _{10} C$ and $m$ that demonstrated a clear linear relationship. This linear dependence was well known from literature, as reported in Cortie and Garrett (1988) and Bergner and Zouhar (2000), and was also highlighted for different materials in Giannella (2021a, b), Giannella (2022) and Annis (2004) where Monte Carlo simulations were similarly adopted. The reader is referred to Bergner and Zouhar (2000) and its references for deepenings.

An example of the residual life cycles predicted for the bar can be seen in Fig. 9. It can be noticed that the best-fit curve provided a non-conservative prediction (88\% of predictions were lower than that), although the prediction was computed with the "best" CGR curve. If considering also the results reported in Giannella (2021a) where another non-conservative prediction was computed with the best-fit parameters, the limitations of deterministic FCG calculations are evident since they are not always able to guarantee either the conservativeness nor the non-conservativeness of their predictions. The need to resort to a more robust stochastic approach appears to be obvious for achieving reliable FCG assessments.

Subsequently, calculations were separately performed at different load levels ranging from 38.2 to $127.2 \mathrm{kN}$. This range was selected so as to produce nominal stresses $\sigma_{\text {nom }}$ ranging from $150 \mathrm{MPa}$, mostly corresponding to a $\Delta K$ threshold level for the considered case study, to $500 \mathrm{MPa}$, mostly corresponding to a stress level close to the material yield stress (Table 2).

Figure 10 shows a Wöhler-like diagram comparing the life predictions and probability of failures with the corresponding stress levels. Similar results were also shown in Fig. 11 in terms of probability density functions. Lognormal distributions were also fitted on the obtained frequencies showing a satisfactory correlation, except for the lowest stress level due to the near-threshold condition (Fig. 10). It can be quantitatively measured what is the impact of each stress level on the estimated life when considering input data variability. This kind of result is generally used for designing purposes according to the damage tolerance
Fig. 8 Correlation matrix for NASGRO parameters $C$, $m, p, \Delta K_{t h, o}$; best-fit parameters are in red

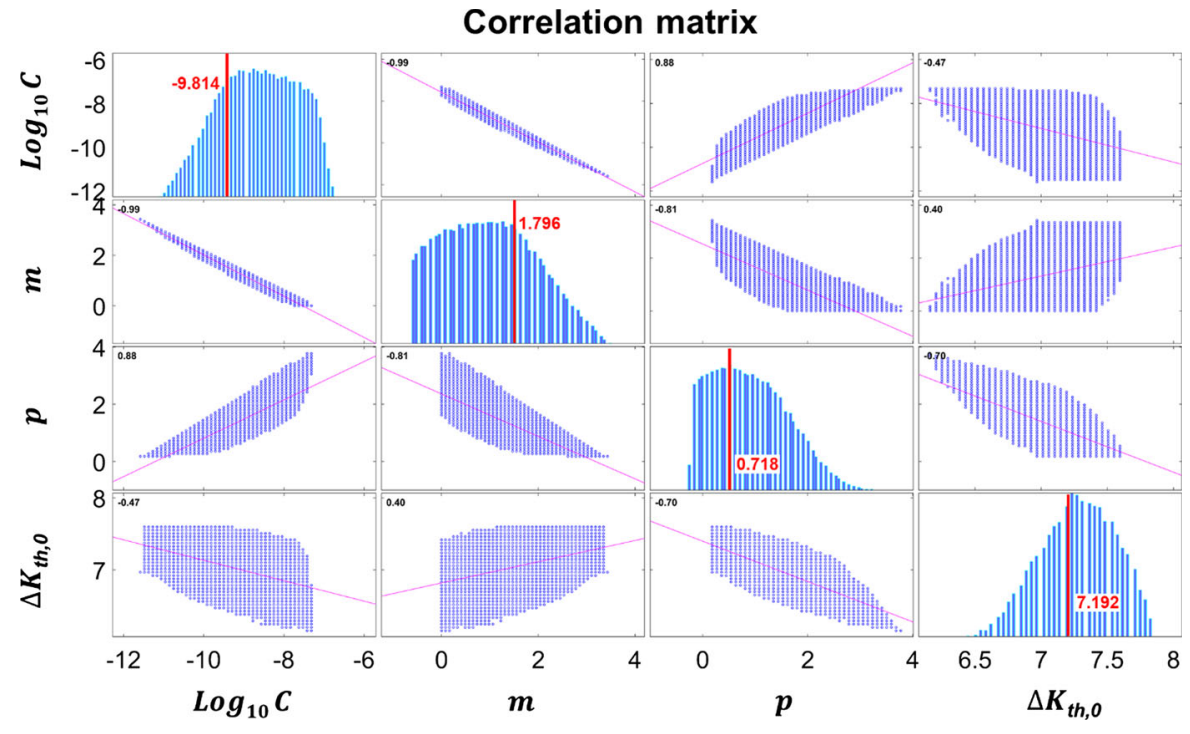


Fig. 9 Simulated crack depth vs. residual life cycles curves

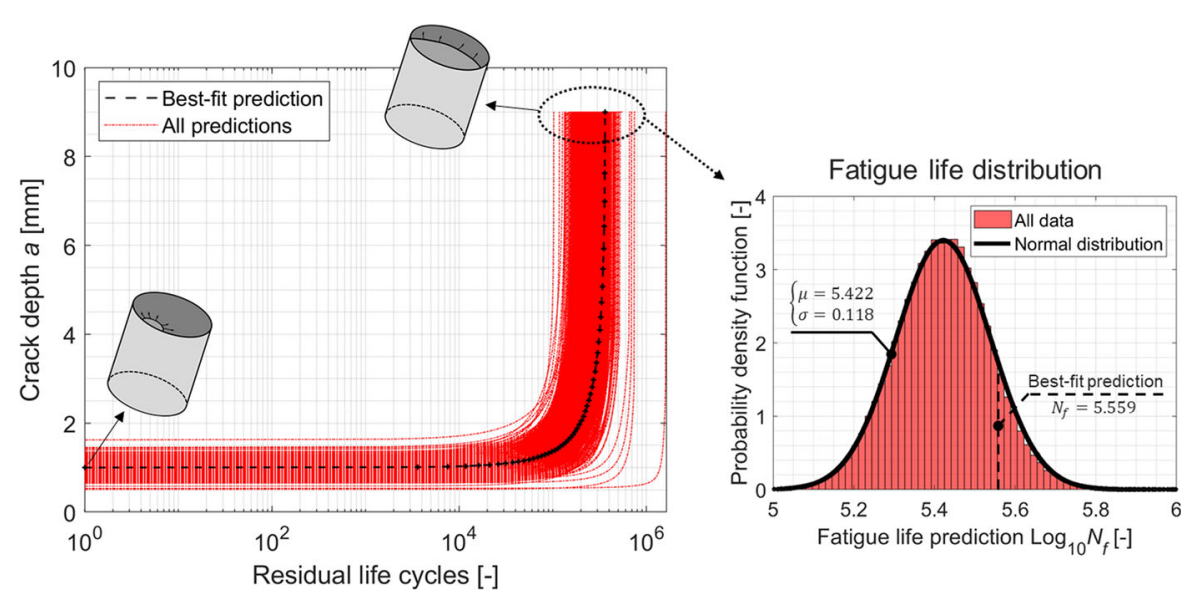

Fig. 10 Stress-life diagram at various stress levels

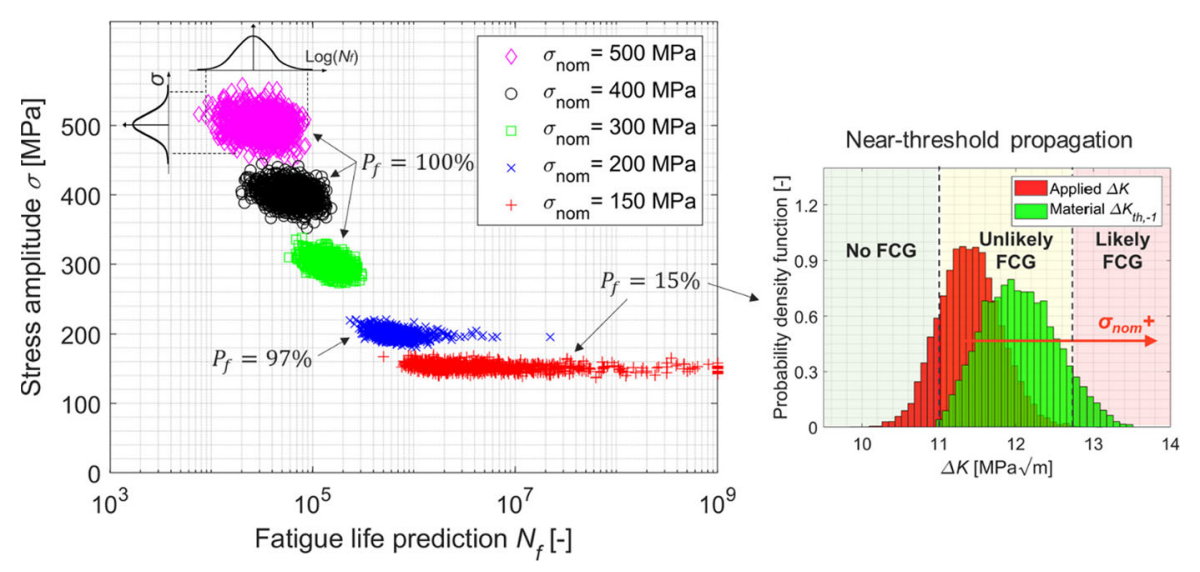

philosophy (Patriarca et al. 2020; MIL-STD-1530D 2016).

A high variability of lives is computed at the highest stress levels. This has to be partially attributed to the fact that very few experimental points were available in the high $\Delta K$ region, in turn producing a large spread of the simulated CGRs, see Fig. 7. Therefore, a lower dispersion of the life predictions obtained at stress levels of 400 and $500 \mathrm{MPa}$ (Figs. 10, 11) should be expected with more experimental data. More specific experimental tests are needed to better define this region of propagation. Nonetheless, the largest spread is obtained for the lowest stress level where near-threshold propagations were computed, see Fig. 10. This was expectable since very long fatigue lives can be obtained when dealing with such near-threshold $\Delta K$ values.

By taking into account multiple sources of uncertainty, it was assessed that the stress level of $150 \mathrm{MPa}$ results in a probability of failure $P_{f}$ of $15 \%$. Namely, only $15 \%$ of all predictions at $150 \mathrm{MPa}$ returned a propagating crack, whereas the remaining $85 \%$ of simulations turned out to have an applied $\Delta K$ lower than $\Delta K_{t h,-1}$, hence a non-propagating crack. This means that the probability of having crack propagation, and then a failure after a certain number of fatigue cycles, was equal to $15 \%$ at $150 \mathrm{MPa}$. With reference to the $200 \mathrm{MPa}$ stress level, only $3 \%$ of predictions did not propagate at all since having an initial $\Delta K$ lower than $\Delta K_{t h,-1}$ and, therefore, a $P_{f}$ of $97 \%$ was derived. Finally, as seen in Fig. 10, all the stress levels higher than $200 \mathrm{MPa}$ returned a $P_{f}$ of $100 \%$. It is worth noting that, with reference to this case study, there is the need of a noteworthy $50 \mathrm{MPa}$ of gap to trigger crack propagation with a high probability. Conversely, there is the need of reducing the applied stress of more than $50 \mathrm{MPa}$ to have a good probability of switching from a very likely $\left(P_{f}=97 \%\right)$ to an unlikely $\left(P_{f}=15 \%\right)$ crack propagation. This gives indications on the safety factors that should be considered when it 


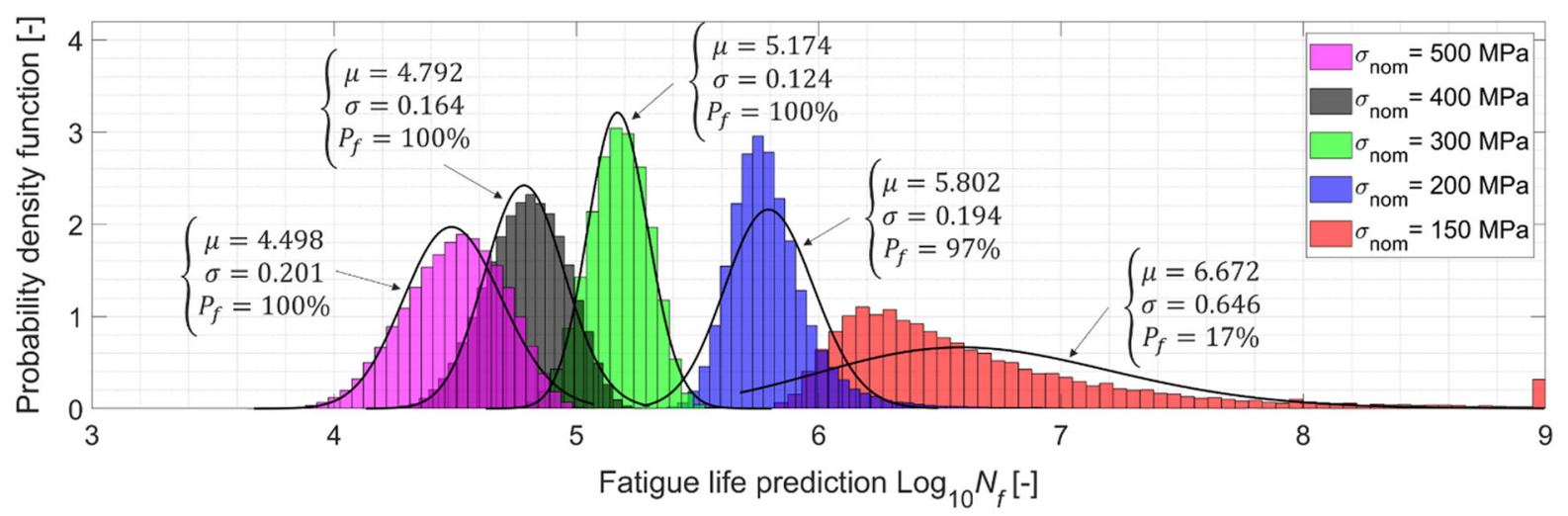

Fig. 11 Probability density functions for the residual life estimates at various stress levels

Fig. 12 Fatigue life predictions for various uncertainty levels of crack size

\section{Crack size uncertainty}

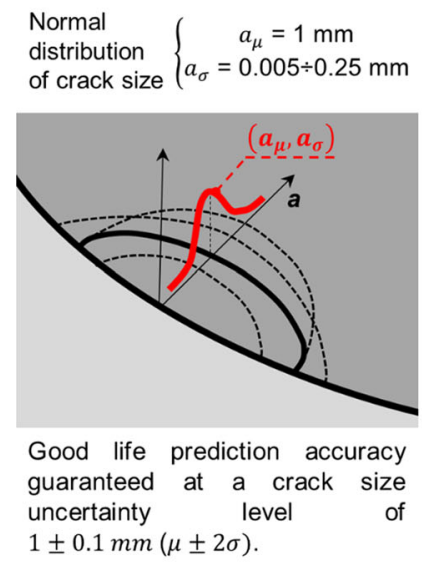

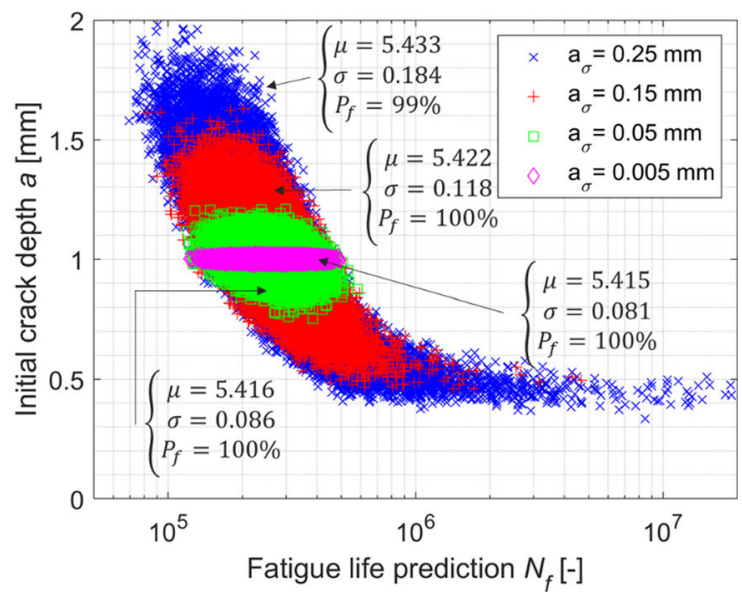

is necessary to guarantee the non-propagation of cracks. Resorting to a robust stochastic approach for FCG assessments is mandatory to tackle these critical safety issues.

\subsection{Sensitivity analysis}

A sensitivity analysis was performed to highlight the influence of the uncertainty of each input parameter on the residual life predictions. Namely, different levels of $a_{\sigma}, D_{\sigma}$ and $F_{\sigma}$ were considered so as to quantify their influence on the predictions, see Figs. 12, 13 and 14. The aim of this sensitivity analysis was to highlight the influence of each contributor of uncertainty on the life predictions, both on the mean value and the dispersion around it. Furthermore, this sensitivity analysis also quantified the levels of uncertainty of input parameters that would not return any improvement on the life prediction accuracy.

With reference to Fig. 12, as obvious, all predictions with larger initial crack depths returned the lowest life predictions. Assuming that life distributions can be approximated by lognormal distributions, mean values and standard deviations calculated at various $a_{\sigma}$ can be compared to each other. It was observed that an $a_{\sigma}$ of $0.05 \mathrm{~mm}$ allowed us to acceptably define the lifespan distribution and furtherly reducing this parameter did not significantly reduce spread of predictions, nor influence the mean value. In other words, knowing that the initial crack depth measures nearly $1 \mathrm{~mm}$ within a range of uncertainty of $1 \pm 0.1 \mathrm{~mm} \mathrm{(} \mu \pm 2 \sigma$, thus with a covering of $95.5 \%$ ) can be sufficient to accurately predict the fatigue life, and further improvements on 
Fig. 13 Fatigue life predictions for various uncertainty levels of diameter

Fig. 14 Fatigue life predictions for various uncertainty levels of load amplitude

\section{Geometrical tolerances}

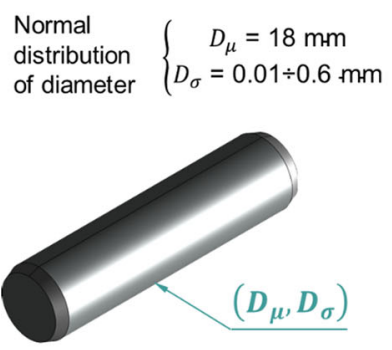

Good life prediction accuracy guaranteed at a diameter uncertainty level of $18 \pm$ $0.054 m(\mu \pm 2 \sigma)$.

\section{Actual loading conditions}

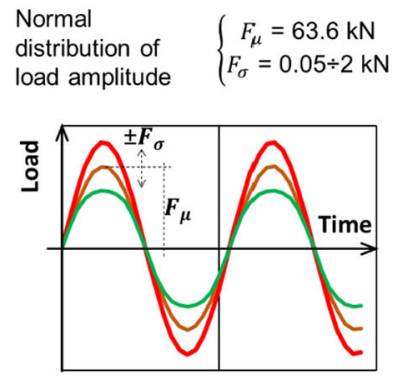

Good life prediction accuracy guaranteed at a load amplitude uncertainty level of $63.6 \pm$ $4 k N(\mu \pm 2 \sigma)$.
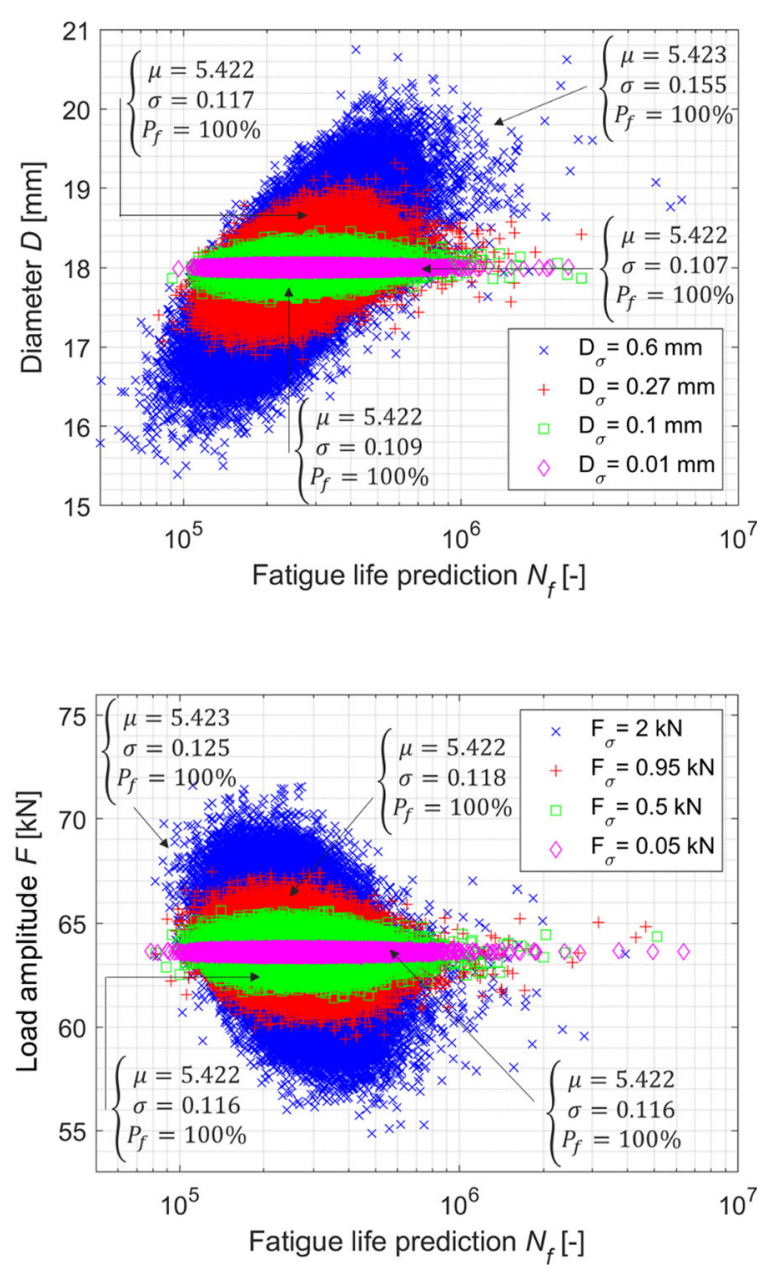

predictions did not vary in a significant way when reducing the uncertainty of the actual loading conditions to a $F_{\sigma}$ lower than $2 \mathrm{kN}$. In other words, knowing that the applied loads can fluctuate within a range of $63.6 \pm 4 \mathrm{kN}(\mu \pm 2 \sigma)$ is sufficient to accurately determine the lifespan distribution. And so, furtherly improving the measure accuracy of loads do not

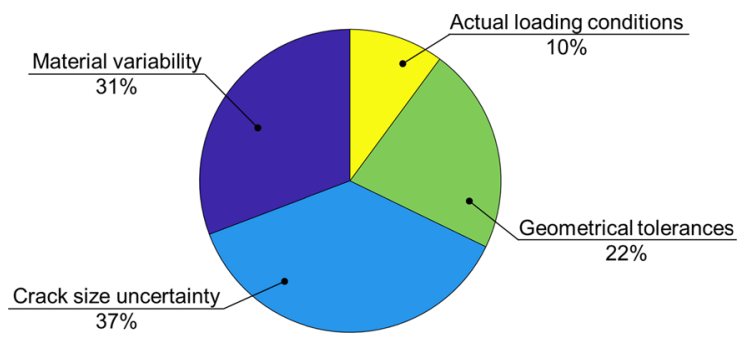

Fig. 15 Ranking of the main contributors affecting a structural integrity assessment 
guarantee that the life predictions of this engineering component results to be more accurate.

\subsection{Discussion}

The final comparison among uncertainty sources of Fig. 15 shows that, during an optimization process, the highest priority should be assigned to the initial crack size distribution, in turn followed by the material scattering and geometrical tolerances, whereas the loading conditions seems to produce the lowest contribution. This partially agrees with comparable results already available in literature, as well as with assumptions made in several works in which only material variability was taken into account (Beretta et al. 2016a; Giannella 2021a, b; Zhu et al. 2018b; Beretta and Carboni 2006). However, quantifying all contributors that can affect safety of structures is fundamental to assess their actual impact on the life predictions. Indeed, it was quantified here that almost two-thirds of the fatigue life scatter resulted to come from only two contributors, i.e. material scattering and crack size uncertainty (Fig. 15). The former cannot be reduced in size but needs to be quantified, whereas the latter has to be always quantified accurately and should be taken into account in every probabilistic life assessment. Only through these evaluations, a higher comprehension on our capability to guarantee the structural safety can be achieved.

It is worth noting that the low contribution of loading conditions was rather expectable since the considered case study was based on a purely axially loaded component. Much higher dependence of predictions on the geometry is expected for components subjected to bending loads, and even higher dependence is expected for cases where cracks start propagating from notches (Niu et al. 2021; Zhu et al. 2018a). Compared with other uncertain parameters, the uncertainty coming from geometric tolerances plays a relevant role, even though it has to be stated that these are more likely controllable contributions.

The initial crack size uncertainty ranked first in influencing the overall uncertainty. However, it has to be stated that this contribution can be up/down scaled depending, not only on its dispersion, but also on the mean value of defects that one has to consider. As a matter of fact, small variations on life predictions are expected with high $\Delta K$ values (e.g. with long cracks). Contrarily, with low $\Delta K$ values (e.g. short cracks), small variations in the crack sizes can lead to large variations in the predictions, see Figs. 10 and 11. Similar conclusions were also reported in Náhlík et al. (2017) and Pokorný et al. (2016a, b).

This investigation has taken into account multisource uncertainties coming from the most important parameters typically affecting a structural integrity assessment. Ranking these contributors is mandatory so as to drive further optimization procedures that can eventually allow for improved and more robust life predictions. Large dispersions of life predictions (Figs. 10, 11, 12, 13, 14) were computed, reaching even more than an order of magnitude of variability, as shown in similar works related to both fatigue (Zhu et al. 2017, 2018a, b; Niu et al. 2021) and fracture (Giannella 2021a, b, 2022; Grell and Laz 2010; Beretta and Carboni 2006; Annis 2004; Virkler et al. 1979). These dispersions cannot be significantly reduced in size by improving the control on only few parameters, but, all of them, or at least the most important ones, need to be controlled at the same time (Fig. 15). If looking at the structural integrity assessment as a process in which many random variables converge, it is clear that a reduction of the life prediction dispersion can be achieved only when all contributors' dispersions are reduced simultaneously.

\section{Conclusions}

Uncertainty and variability of input parameters for fatigue crack-growth calculations directly contribute to reduce the reliability of predictions and to increase the risk of unexpected structural failures. This work presented a stochastic approach to fatigue crackgrowth predictions applied to a round bar under tension-compression loading by considering multisource uncertainties.

The accuracy in measuring the initial crack sizes turned out to be the most relevant contribution to spread the lifespan distribution, followed by the material scattering, by the geometrical tolerances and by the loading conditions. Only by quantifying all the contributors that can potentially endanger the safety of structures, greater understanding of our capability to predict the actual life of structures can be reached.

Noteworthy spreads of predictions were computed, thus highlighting the need to resort to probabilistic 
FCG procedures comprehensive of multiple uncertainty sources. Being the structural integrity assessment, a process in which many random variables converge, improvements in the life prediction accuracy can be achieved only when all contributors' dispersions are reduced simultaneously.

Funding Open access funding provided by Università degli Studi di Salerno within the CRUI-CARE Agreement.

Open Access This article is licensed under a Creative Commons Attribution 4.0 International License, which permits use, sharing, adaptation, distribution and reproduction in any medium or format, as long as you give appropriate credit to the original author(s) and the source, provide a link to the Creative Commons licence, and indicate if changes were made. The images or other third party material in this article are included in the article's Creative Commons licence, unless indicated otherwise in a credit line to the material. If material is not included in the article's Creative Commons licence and your intended use is not permitted by statutory regulation or exceeds the permitted use, you will need to obtain permission directly from the copyright holder. To view a copy of this licence, visit http://creativecommons.org/licenses/by/4.0/.

\section{References}

Annis C (2004) Probabilistic life prediction isn't as easy as it looks. J ASTM Int 1(2):1-12. https://doi.org/10.1520/ JAI11557

Armentani E, Greco A, De Luca A, Sepe R (2020) Probabilistic analysis of fatigue behavior of single lap riveted joints. Appl Sci 10:3379. https://doi.org/10.3390/app10103379

Ayhan AO, Demir O (2021) Computational modeling of threedimensional mixed mode-I/II/III fatigue crack growth problems and experiments. Comput Struct 243:106399. https://doi.org/10.1016/j.compstruc.2020.106399

Beretta S, Carboni M (2004) Application of fatigue crack growth algorithms to railway axles and comparison of two steel grades. Proc Inst Mech Eng F J Rail Rapid Transit 218:317. https://doi.org/10.1243/0954409043125888

Beretta S, Carboni M (2006) Experiments and stochastic model for propagation lifetime of railway axles. Eng Fract Mech 73:2627-2641. https://doi.org/10.1016/j.engfracmech.2006. 04.024

Beretta S, Regazzi D (2016) Probabilistic fatigue assessment for railway axles and derivation of a simple format for damage calculations. Int J Fatigue 86:13-23. https://doi.org/10. 1016/j.ijfatigue.2015.08.010

Beretta S, Carboni M, Fiore G, Lo Conte A (2010) Corrosionfatigue of $\mathrm{A} 1 \mathrm{~N}$ railway axle steel exposed to rainwater. Int J Fatigue 32:952-961. https://doi.org/10.1016/j.ijfatigue. 2009.08.003

Beretta S, Foletti S, Rusconi E, Riva A, Socie D (2016a) A lognormal format for failure probability under LCF: concept, validation and definition of design curve. Int J Fatigue 82:2-11. https://doi.org/10.1016/j.ijfatigue.2015.08.027
Beretta S, Carboni M, Regazzi D (2016b) Load interaction effects in propagation lifetime and inspections of railway axles. Int J Fatigue 91(2):423-433. https://doi.org/10.1016/ j.ijfatigue.2016.03.009

Bergner F, Zouhar G (2000) A new approach to the correlation between the coefficient and the exponent in the power law equation of fatigue crack growth. Int J Fatigue 22(3): 229-239. https://doi.org/10.1016/S0142-1123(99)00123-1

Caggiano A, Zhang J, Alfieri V, Caiazzo F, Gao R, Teti R (2019) Machine learning-based image processing for on-line defect recognition in additive manufacturing. CIRP Ann 68(1):451-454. https://doi.org/10.1016/j.cirp.2019.03.021

Caggiano A, Teti R, Alfieri V, Caiazzo F (2021) Automated laser polishing for surface finish enhancement of additive manufactured components for the automotive industry. Prod Eng Res Dev 15(1):109117. https://doi.org/10.1007/ s11740-020-01007-1

Caiazzo F, Alfieri V, Corrado G, Argenio P (2017) Laser powder-bed fusion of Inconel 718 to manufacture turbine blades. Int J Adv Manuf Technol 93(9-12):4023-4031. https://doi.org/10.1007/s00170-017-0839-3

Carlone P, Citarella R, Sonne MR, Hattel JH (2016) Multiple crack growth prediction in AA2024-T3 friction stir welded joints, including manufacturing effects. Int $\mathrm{J}$ Fatigue 90:69-77. https://doi.org/10.1016/j.ijfatigue.2016.04.004

Chernatynskiy A, Phillpot SR, LeSar R (2013) Uncertainty quantification in multiscale simulation of materials: a prospective. Annu Rev Mater Res 43(1):157-182. https:// doi.org/10.1146/annurev-matsci-071312-121708

Ciavarella M, Papangelo A (2018) On the distribution and scatter of fatigue lives obtained by integration of crack growth curves: does initial crack size distribution matter? Eng Fract Mech 191:111-124. https://doi.org/10.1016/j. engfracmech.2018.01.019

Citarella R, Apicella A (2006) Advanced design concepts and maintenance by integrated risk evaluation for aerostructures. Struct Durab Health Monit 2(3):183-196. https://doi. org/10.3970/sdhm.2006.002.183

Citarella R, Perrella M (2015) Robust design of a polygonal shaft-hub coupling. Frattura Ed Integrità Strutturale 34:554-563. https://doi.org/10.3221/IGF-ESIS.34.61

Citarella R, Giannella V, Vivo E, Mazzeo M (2016) FEMDBEM approach for crack propagation in a low pressure aeroengine turbine vane segment. Theoret Appl Fract Mech 86:143-152. https://doi.org/10.1016/j.tafmec.2016. 05.004

Citarella R, Giannella V, Lepore M, Dhondt G (2018) Dual boundary element method and finite element method for mixed-mode crack propagation simulations in a cracked hollow shaft. Fatigue Fract Eng Mater Struct 41(1):84-98. https://doi.org/10.1111/ffe.12655

Cortie MB, Garrett GG (1988) On the correlation between the C and $\mathrm{m}$ in the Paris equation for fatigue crack propagation. Eng Fract Mech 30(1):49-58. https://doi.org/10.1016/ 0013-7944(88)90254-8

El-Haddad MH, Smith KN, Topper TH (1979) Fatigue crack propagation of short crack. Trans ASME J Eng Mater Technol 101:42-46. https://doi.org/10.1115/1.3443647

Elber W (1970) Fatigue crack closure under cyclic tension. Eng Fract Mech 2:37-45. https://doi.org/10.1016/00137944(70)90028-7 
Elber W (1971) The significance of fatigue crack closure. In: Rosenfeld M (ed) Damage tolerance in aircraft structures. ASTM International, West Conshohocken, pp 230-242

Endeshaw HB, Ekwaro-Osire S, Alemayehu FM, Dias JP (2017) Evaluation of fatigue crack propagation of gears considering uncertainties in loading and material properties. Sustainability 9(12):2200. https://doi.org/10.3390/ su9122200

Fellinger J, Citarella R, Giannella V et al (2018) Overview of fatigue life assessment of baffles in Wendelstein 7-X. Fusion Eng Des 136:292-297. https://doi.org/10.1016/j. fusengdes.2018.02.011

Forman RG, Mettu SR (1990) Behavior of surface and corner cracks subjected to tensile and bending loads in Ti-6Al-4V alloy

Giannella V (2021a) Stochastic approach to fatigue crackgrowth simulation for a railway axle under input data variability. Int J Fatigue 144:106044. https://doi.org/10. 1016/j.ijfatigue.2020.106044

Giannella V (2021b) Fatigue crack-growth predictions for a railway axle under material data variability. IOP Conf Ser Mater Sci Eng 1038:012062. https://doi.org/10.1088/1757899X/1038/1/012062

Giannella V (2022) On the statistical nature of fatigue crackgrowth through Monte Carlo simulations and experimental data. IOP Conf Ser Mater Sci Eng 1214(1):012020. https:// doi.org/10.1088/1757-899X/1214/1/012020

Giannella V, Perrella M (2019) Multi-axial fatigue numerical crack propagations in cruciform specimens. Frattura Ed Integr Strutturale 13(48):639-647. https://doi.org/10.3221/ IGF-ESIS.48.61

Giannella V, Fellinger J, Perrella M, Citarella R (2017a) Fatigue life assessment in lateral support element of a magnet for nuclear fusion experiment "Wendelstein 7-X." Eng Fract Mech 178:243-257. https://doi.org/10.1016/j. engfracmech.2017.04.033

Giannella V, Perrella M, Citarella R (2017b) Efficient FEMDBEM coupled approach for crack propagation simulations. Theoret Appl Fract Mech 91:76-85. https://doi.org/ 10.1016/j.tafmec.2017.04.003

Giannella V, Citarella R, Fellinger J, Esposito R (2018a) LCF assessment on heat shield components of nuclear fusion experiment wendelstein $7-\mathrm{X}$ by critical plane criteria. Procedia Struct Integr 8:318-331. https://doi.org/10.1016/ j.prostr.2017.12.033

Giannella V, Vivo E, Mazzeo M, Citarella R (2018b) FEMDBEM approach to simulate crack propagation in a turbine vane segment undergoing a fatigue load spectrum. Procedia Struct Integr 12:479-491. https://doi.org/10.1016/j. prostr.2018.11.070

Giannella V, Dhondt G, Kontermann C, Citarella R (2019a) Combined static-cyclic multi-axial crack propagation in cruciform specimens. Int J Fatigue 123:296-307. https:// doi.org/10.1016/j.ijfatigue.2019.02.029

Giannella V, Citarella R, Perrella M, Shlyannikov V (2019b) Surface crack modelling in an engine compressor disc. Theoret Appl Fract Mech 103:102279. https://doi.org/10. 1016/j.tafmec.2019.102279

Giannella V, Sepe R, De Michele G, Esposito R (2021) Deterministic fatigue crack-growth simulations for a railway axle by dual boundary element method. IOP Conf Ser
Mater Sci Eng 1038:012080. https://doi.org/10.1088/1757899X/1038/1/012080

Grell WA, Laz PJ (2010) Probabilistic fatigue life prediction using AFGROW and accounting for material variability. Int J Fatigue 32(7):1042-1049. https://doi.org/10.1016/j. ijfatigue.2009.12.001

Guida M, Penta F (2010) A Bayesian analysis of fatigue data. Struct Saf 32(1):64-76. https://doi.org/10.1016/j.strusafe. 2009.08.001

He W, Liu J, Xie D (2015) Probabilistic life assessment on fatigue crack growth in mixed-mode by coupling of Kriging model and finite element analysis. Eng Fract Mech 139:56-77. https://doi.org/10.1016/j.engfracmech.2015. 03.040

Hu D, Su X, Liu X, Mao J, Shan X, Wang R (2020) Bayesianbased probabilistic fatigue crack growth evaluation combined with machine-learning-assisted GPR. Eng Fract Mech 229:106933. https://doi.org/10.1016/j.engfracmech. 2020.106933

Hu Y, Wu S, Withers PJ, Cao H, Chen P, Zhang Y, Shen Z, Vojtek T, Hutar P (2021) Corrosion fatigue lifetime assessment of high-speed railway axle EA4T steel with artificial scratch. Eng Fract Mech 245:107588. https://doi. org/10.1016/j.engfracmech.2021.107588

James LA, Mills WJ (1988) Review and synthesis of stress intensity factor solutions applicable to cracks in bolts. Eng Fract Mech 30(5):641-654. https://doi.org/10.1016/00137944(88)90156-7

Klawonn A, Hagenacker A, Beck T (2020) A probabilistic Haigh diagram based on a weakest link approach. Int J Fatigue 133:105419. https://doi.org/10.1016/j.ijfatigue. 2019.105419

Larsen JM, Jha SK, Szczepanski CJ, Caton MJ, John R, Rosenberger AH, Buchanan DJ, Golden PJ, Jira JR (2013) Reducing uncertainty in fatigue life limits of turbine engine alloys. Int J Fatigue 57:103-112. https://doi.org/10.1016/j. ijfatigue.2013.01.012

Luke M, Varfolomeev I, Lütkepohl K, Esderts A (2011) Fatigue crack growth in railway axles: assessment concept and validation tests. Eng Fract Mech 78(5):714-730. https:// doi.org/10.1016/j.engfracmech.2010.11.024

Maierhofer J, Pippan R, Gänser H-P (2014) Modified NASGRO equation for physically short cracks. Int $\mathrm{J}$ Fatigue 59:200-207. https://doi.org/10.1016/j.ijfatigue.2013.08. 019

MATLAB, R2020a (2019) The MathWorks Inc, Natick

MIL-STD-1530D (2016) Department of Defense Standard Practice. Aircraft structural integrity program (ASIP). http://everyspec.com/MIL-STD/MIL-STD-1500-1599/ MIL-STD-1530D_CHG-1_55391/. Accessed 8 Apr 2021

Náhlík L, Pokorný P, Š evčík M, Fajkoš R, Matušek P, Hutař P (2017) Fatigue lifetime estimation of railway axles. Eng Fail Anal 73:139-157. https://doi.org/10.1016/j. engfailanal.2016.12.014

NASGRO ${ }^{\circledR}(2019)$ Fracture mechanics \& fatigue crack growth analysis software. www.nasgro.swri.org. Accessed 8 Apr 2021

Newman JC (1984) A crack opening stress equation for fatigue crack growth. Int J Fract 24:R131-R135. https://doi.org/ 10.1007/BF00020751 
Niu X-P, Wang R-Z, Liao D, Zhu S-P, Zhang X-C, Keshtegar B (2021) Probabilistic modeling of uncertainties in fatigue reliability analysis of turbine bladed disks. Int J Fatigue 142:105912. https://doi.org/10.1016/j.ijfatigue.2020. 105912

Patriarca L, Beretta S, Foletti S, Riva A, Parodi S (2020) A probabilistic framework to define the design stress and acceptable defects under combined-cycle fatigue conditions. Eng Fract Mech 224:106784. https://doi.org/10. 1016/j.engfracmech.2019.106784

Pokorný P, Náhlík L, Hutař P (2016a) Influence of variable stress ratio during train operation on residual fatigue lifetime of railway axles. Procedia Struct Integr 2:3585-3592. https://doi.org/10.1016/j.prostr.2016.06.447

Pokorný P, Hutař P, Náhlík L (2016b) Residual fatigue lifetime estimation of railway axles for various loading spectra. Theor Appl Fract Mech 82:25-32. https://doi.org/10.1016/ j.tafmec.2015.06.007

Pokorný P, Vojtek T, Nahlík L, Hutar P (2017) Crack closure in near-threshold fatigue crack propagation in railway axle steel EA4T. Eng Fract Mech 185:2-19. https://doi.org/10. 1016/j.engfracmech.2017.02.013

Project MARAXIL (2012) Manufacturing railway axles with improved lifetime. http://maraxil.mecc.polimi.it/. Accessed 8 Apr 2021

Pugno N, Ciavarella M, Cornetti P, Carpinteri A (2006) A generalized Paris' law for fatigue crack growth. J Mech Phys Solids 54(7):1333-1349. https://doi.org/10.1016/j. jmps.2006.01.007

Romano S, Beretta S, Miccoli S, Gschweitl M (2020) Probabilistic framework for defect tolerant fatigue assessment of additively manufactured parts applied to a space component. In: Shamsaei N, Daniewicz S, Hrabe N, Beretta S, Waller J, Seifi M (eds) Structural integrity of additive manufactured parts. ASTM International, West Conshohocken, pp 526-539

Roy CJ, Oberkampf WL (2011) A comprehensive framework for verification, validation, and uncertainty quantification in scientific computing. Comput Methods Appl Mech Eng 200(25):2131-2144. https://doi.org/10.1016/j.cma.2011. 03.016

Rubino F, Parmar H, Esperto V, Carlone P (2020) Ultrasonic welding of magnesium alloys: a review. Mater Manuf Process 35(10):1051-1068. https://doi.org/10.1080/ 10426914.2020.1758330

Rubino F, Canale G, Sathujoda P (2021) The effect of manufacturing defects on the high-cycle fatigue of electronbeam-welded Ti-6Al-4V titanium alloy: experimental and numerical analysis. Multidiscip Model Mater Struct 17(4):796-813. https://doi.org/10.1108/MMMS-09-20200230

Sandberg D, Mansour R, Olsson M (2017) Fatigue probability assessment including aleatory and epistemic uncertainty with application to gas turbine compressor blades. Int $\mathbf{J}$ Fatigue 95:132-142. https://doi.org/10.1016/j.ijfatigue. 2016.10.001
Sepe R, Greco A, De Luca A, Armentani E, Berto F (2019) Experimental and FEM numerical assessment of multiaxial fatigue failure criteria for a rolling Stock's seats structure. Eng Fail Anal 102:303-317. https://doi.org/10.1016/j. engfailanal.2019.04.065

Shlyannikov V, Yarullin R, Yakovlev M, Giannella V, Citarella R (2021) Mixed-mode crack growth simulation in aviation engine compressor disk. Eng Fract Mech 246:107617. https://doi.org/10.1016/j.engfracmech.2021.107617

Varfolomeev I, Luke M, Moroz S, Burdack M (2010) Experimental and numerical study of fatigue crack growth behaviour in the threshold range. In: ECF 2010, 18th European Conference on Fracture. CD-ROM: fracture of materials and fractures from micro to macro scale, 30.08.03.09.2010. Dresden, p 519.

Virkler DA, Hillberry B, Goel PK (1979) The statistical nature of fatigue crack propagation. J Eng Mater Technol 101(2):148-153. https://doi.org/10.1115/1.3443666

Vojtek T, Pokorný P, Kubena I, Nahlík L, Fajkos R, Hutar P (2019) Quantitative dependence of oxide-induced crack closure on air humidity for railway axle steel. Int J Fatigue 123:213-224. https://doi.org/10.1016/j.ijfatigue.2019.02. 019

Wu SC, Zhang SQ, Xu ZW, Kang GZ, Cai LX (2016) Cyclic plastic strain based damage tolerance for railway axles in China. Int J Fatigue 93:64-70. https://doi.org/10.1016/j. ijfatigue.2016.08.006

Zhan H, Zhao W, Wang G (2000) Manufacturing turbine blisks. Aircraft Eng Aerospace Technol 72(3):247-252. https:// doi.org/10.1108/00022660010332032

Zhu SP, Foletti S, Beretta S (2017) Probabilistic framework for multiaxial LCF assessment under material variability. Int J Fatigue 103:371-385. https://doi.org/10.1016/j.ijfatigue. 2017.06.019

Zhu SP, Liu Q, Peng W, Zhang X-C (2018a) Computationalexperimental approaches for fatigue reliability assessment of turbine bladed disks. Int J Mech Sci 142-143:502-517. https://doi.org/10.1016/j.ijmecsci.2018.04.050

Zhu SP, Liu Q, Zhou J, Yu ZY (2018b) Fatigue reliability assessment of turbine discs under multi-source uncertainties. Fatigue Fract Eng Mater Struct 41(6):1291-1305. https://doi.org/10.1111/ffe.12772

Zhu SP, Liu Q, Lei Q, Wang Q (2018c) Probabilistic fatigue life prediction and reliability assessment of a high pressure turbine disc considering load variations. Int J Damage Mech 27(10):1569-1588. https://doi.org/10.1177/ 1056789517737132

Zhu SP, Keshtegar B, Bagheri M, Hao P, Trung N-T (2020) Novel hybrid robust method for uncertain reliability analysis using finite conjugate map. Comput Methods Appl Mech Eng 371:113309. https://doi.org/10.1016/j.cma. 2020.113309

Publisher's Note Springer Nature remains neutral with regard to jurisdictional claims in published maps and institutional affiliations. 